\title{
Development and psychometrics properties of a questionnaire to measure the general perception of COVID-19 risk in Iran: A structural equation modeling approach
}

\section{Ezat Samadipour}

Sabzevar University of Medical Sciences

Fatemeh Ghardashi ( $\nabla$ f2.ghardashi@gmail.com )

Sabzevar University of Medical Sciences

\section{Research Article}

Keywords: Health, Perception, Surveys and Questionnaires, Covid-19, Disasters, Validity

Posted Date: May 13th, 2021

DOI: https://doi.org/10.21203/rs.3.rs-454209/v1

License: (c) (i) This work is licensed under a Creative Commons Attribution 4.0 International License. Read Full License 


\section{Abstract}

Background Risk perception in this COVID19 situation is important and its measurement tool can be useful in terms of the making of social health policy. This study aimed to develop and psychometrics properties of a new scale, for assessing general perception of Covid-19 risk (GPCOVID-19R) in Iran.

Methods A methodological study with a structural equation model approach was used to develop and psychometrics the GPCOVID-19 R questionnaire. First, qualitative method, an operational definition of risk perception of COVID-19 was presented by 10 experts. The item generation and scale development were performed through literature review, a qualitative approach, and interviews with an expert panel. Then, the psychometric properties of the scale were evaluated by means of cross-sectional studies. Exploratory factor analysis, confirmatory factor analysis and scale correlation were performed using Amos software version 23.

Results 304 users of social groups in Tehran province participated in completing the online questionnaire. The results of psychometric properties of the questionnaire indicate the desired validity and reliability. The exploratory factor analysis revealed five factors, containing 20 items. The confirmatory factor analysis showed a model with appropriate fitness for the data.

Conclusion The results of the study suggest that GPCOVID-19R is a reliable and valid tool for measuring Iranians' general perception of Covid-19 risk.

\section{Background}

SARS-Cove-2 virus is a new type of corona virus and a natural biological hazard. This emerging threat started in China (Wuhan) and has affected the whole world in a matter of months. As the global prevalence of the disease increased, the World Health Organization (WHO) declared on January 11, 2019, the corona virus as the sixth public health emergency worldwide, threatening not only China but the world as a whole(1). To date, the WHO has approved more than 141,754,944 cases of COVID-19 and reported $3,025,835$ deaths worldwide (April 20, 2021)(2). Outbreak control of Covid-19 is limited to identifying, treating and isolating infected individuals, tracking and quarantining them, reducing travel and promoting public participation to break the transmission chain $(3,4)$. Therefore, to prevent the spread of the corona virus, health workers, people and governments must work together. Experiences in controlling the prevalence of infectious diseases such as SARS, pandemic influenza and swine flu epidemics have shown that the strategies adopted and their success depend to a large extent on the risk perception of the people of those areas $(5,6)$.

Risk perception refers to the subjective judgment to understand risks in the society and is considered in general literature as the appropriate behavior when confronted with risks $(7,8)$. The main approaches in risk perception studies are rationalism or structuralism (9). The rational approach puts an emphasis on individual cognitive processes and assumes that risk will lead to a process of rational decision-making for protection and precautionary behaviors in the individual. Therefore, studies based on the rationalist 
paradigm tend to model, describe and predict the behavioral results of different risks (10-12). On the other hand, the structuralism approach considers risk as the context of social structures and assumes that an individual's decisions and decision-making processes are shaped and restricted in the social environment $(13,14)$.

Risk perception studies have been conducted in the fields of psychology and cultural theory, and a few researches have been carried out in both (15-17). It started in the psychological paradigm with Starr's initial efforts to weigh technological risks (18). Then, inspired by Starr's studies, Slavic expanded his theory and presented the psychometric model theory, based on which the two main factors of risk perception in individuals are considered to be "fear and unknown risk factor" (19). The basis of the cultural theory lies in the process of risk perception in the society through the macro-sociological perspective introduced by Douglas and Wildavsky $(17,20)$. Social psychologists, as well as sociologist and anthropologists, argue that risk assessment and acceptance in the individuals are influenced by the person's worldview, subcultures and his/her affiliation with corresponding groups within a culture, and it is assumed that society shapes the response to a risk (21). In the cultural approach, risk perception is the executive process of norms, values, and cultural activities in a group of people $(16,20)$. Kaspersone et al. (1988) suggested the term "social amplification of risk" (22).

Renn (2000) divided risk perception into individual and collective demonstrations and considered 4 levels for it and each higher level includes the levels below. The first level includes heuristics of individual and collective information process; the second level is cognitive and emotional factors; the third level includes political and social actions and the fourth level is the cultural background. This level is the last level of risk perception which encompasses all the levels below $(18,23-25)$. As a crucial indicator in risk communications, public risk perception measurement is the main concern of executive crisis managers. In most studies, the psychometric model has been used to design a risk perception questionnaire $(26,27)$. Ripple (2002) made efforts to present an instrument to measure risk perception based on the cultural pattern, but it has not been used very much in risk perception studies (21).Samadipour (2019) designed a risk perception model of natural disasters for Iranian people by presenting a construct consisted of three dimensions of individual, society, and context in each of the four stages of crisis management. The risk perception model of Iranian people consists of five main constructs that shape the risk perception which are authority, will, cognition, feeling, and sociopolitical and cultural factors. Formation of each of these factors occurs in the context of reason, science, and beliefs $(28,29)$.

We can conclude from what was mentioned above that despite rich theoretical bases in the field of risk perception of disasters, accurate and comparable measurements for risk perception have not been created yet. Some studies are merely theoretic and have never been practiced and some are quantitative studies with researcher-made instruments whose validity and reliability have not been measured. Considering the spread of COVID-19 biohazard pandemic in Iran and the world, and the fact that it has been determined that the only way to control it is the contribution of all the people in the world in following health guidelines and physical distancing, public risk perception has become a major management challenge for politicians and officials involved in controlling the epidemic. Risk perception in this COVID19 situation is important 
and its measurement tool can be useful in terms of the making of social policy. Thus, the present study has been conducted with the aim of design and psychometric of a questionnaire to measure the Iranians' risk perception of COVID-19.

\section{Methods}

\section{Study design and setting}

The present study is a methodology research which aims to develop psychometrically analyze "general perception of Covid-19 risk (GPCOVID-19R) questionnaire in April 2020. This questionnaire has been prepared based on four stages of Schneider et al. $(2004)(30,31)$

\subsection{Context, concept definition}

.The first step: In order to achieve an operational definition of the concept of risk perception a conventional qualitative content analysis study was used. 10 experts in various specialties related to public perception of risk of Covid-19 disease participated in semi-structured interviews. In that study, 3 PhDs in disaster and emergency management, 1 psychologist, 3 members of the study population, 2 nursing educators and 1 cleric. The contents of the interviews were analyzed based on the approach of Graneheim\& Lundman (2004) Using the latent content method (32).

\section{2 | Item development process}

Second step: The items of the public COVID-19 risk perception questionnaire were created based on the features in the operational definition of the concept, literature review, and the results of studying the factors affecting Iranians' risk perception of COVID-19 (29). The literature review was performed by searching in databases such as Web of Science, Pub Med, Science Direct, and Google Scholar search engine without any time limitations using the keywords of risk perception, crisis, natural disaster, and risk perception questionnaire.

\section{3 | Statistical analysis/ Psychometric evaluation}

In the third step of the research, three methods of face, content, and construct validity were used to ensure the validity of the questionnaire.

Face validity (qualitative and quantitative): In the qualitative method, the questionnaire was emailed to 10 participants and they were asked to give their opinions on the difficulty level, appropriateness level, and ambiguity of each item. After modifying some items based on the opinion of participants, face validity was quantitatively reviewed in the next step using item impact method. In the item impact method, if the obtained score for each item is equal to or more than 1.5 , the statement is considered appropriate and will remain in the questionnaire $(23,24)$. In this step, 9 items were eliminated.

Content validity: Qualitative and quantitative methods were used respectively to review the content validity. In the qualitative method, the evaluation instruments included grammatical correctness, using proper 
words, importance of items, and putting the items in their proper places. At this point, the questionnaire which consisted of 56 items were emailed along with the operational definitions of their main components to 5 experts who had experience in qualitative work and tool-making, and disaster health experts.

Modifications were made based on their suggestions. In the quantitative content validity method, content validity ratio and content validity index were employed.

Content validity ratio (CVR): The Lawshe model was utilized in this study (33), and experts were asked to review each item based on a 3-part scale (it is essential, it is useful but not essential, it is not essential). Based on the Lawshe Table (For evaluation of 5 experts), a minimum acceptable value of 0.99 was considered (34-36). CVR strict method was used in this study, which means that only essential items with put in the content validity ratio formula (37). At the end of this stage, only 32 items were left.

Content validity index (CVI): Experts were asked to review each item in terms of relativity to the intended concept on a 4- point Likert response (from not being relevant to completely relevant). In this research, S$\mathrm{CVI} /$ Ave was calculated. That is, the ratio of items that received a score of 3 or 4 from all the experts, items that received a score of 0.79 and bigger, were kept. Items with a score of 0.7 to 0.78 were modified and revised, and others were taken out (38). At the end, 26 times remained.

Construct validity: Exploratory and confirmatory factor analyses were performed using Amos software version 23. Exploratory factor analysis (Varimax orthogonal rotation method) was used to investigate the internal relationship of variables and to discover variable categories that have the highest correlation (39, 40). Factor analysis is one of the most important steps in designing new instruments (41). The cut-off point of 0.30 was considered in this study as the minimum factor load to maintain the statement extracted from factor analysis. After reviewing the construct validity, 20 items were confirmed for GPCOVID-19R questionnaire.

In the fourth step, the internal consistency method (Cronbach's alpha) was used to determine the reliability of the questionnaire. Cronbach's alpha indicates the appropriateness of the group of items that measure a construct. For a good and sufficient internal consistency, the Cronbach's alpha should be between 0.7 and $0.8(22)$.

\section{4 | Participants / Sampling Method}

Sampling size: In the confirmatory factor analysis (CFA), the sample size should be at least 5 to 10 samples per variable (34). Therefore, the sample size in this study with 26 items was 300 people.

Inclusion and Exclusion Criteria: The inclusion criteria included being Iranian, an internet user, and willingness to participate in the study, and the exclusion criterion was not completing the questionnaire.

Data Collection: The population under study included all internet users who were members of Telegram and WhatsApp groups. Sampling methods were convenience sampling (available) and snowball sampling and participation was voluntary. With cooperation from the group's administrator, the link to the online COVID-19 RPRQ (address: https://samadi.porseshnameonline.com/form/q2) was pinned to the top of 
those groups that the researchers themselves were members of. The group administrator encouraged members to fill out the questionnaire and at the end, they were asked to post the link of the questionnaire in other social media groups.

The questionnaire consisted of two parts: demographics (5 questions) and risk perception question part which was consisted of 26 items with five-choice Likert answers (agree, somewhat agree, no opinion, somewhat disagree, disagree).

Iranians' GPCOVID-19R questionnaire was made available to internet users in Tehran for two weeks, starting from March $25^{\text {th }}$ ( 45 days after the first official COVID death in the city of Qom). A total of 304 questionnaires were completed.

Ethical considerations: Ethical considerations were voluntary participation and anonymous questionnaires. Only one code was assigned to each questionnaire, thus the identity of the user was preserved. Filling out the questionnaire was completely optional and users could exit the study whenever they felt reluctant to continue by clicking on the "completed" button.

\section{Results}

\section{1 | concept definition}

The questionnaire was developed based on Schneider's 4 stages. In the first stage and with a qualitative method, an operational definition of COVID-19 perception was presented by 10 experts. Accordingly, the definition of a general perception of risk of Covid-19 disease is as follows: "Each person's mental judgment in five dimensions, cognitive, emotional, social, cultural and political about the Covid-19 disease crisis and the choice of appropriate behavior".

\section{2 | Item development process}

In the second stage, 136 items were originally composed. The items were reviewed several times by the research team. In the initial review, 40 items were eliminated because of repetitions and content overlap, and 65 items remained in the secondary review.

\subsection{Statistical analysis/ Psychometric evaluation}

In the third stage of the research, the face validity review (qualitative and quantitative) led to the elimination of 9 items (56 remain). The obtained content validity ratio for items of COVID-19 perception risk questionnaire resulted in removing another 24 items (32 remain). Also, based on the result of the calculated content validity index, another 6 items were taken out. 26 items remain in the end which had received the acceptable score (0.5-1) for three indicators of relevancy, simplicity, and clarity. In the fourth stage. After implementing and calculating the Cronbach's alpha and construct validity assessment, the number of items decreased to 20 (Fig 1). 
Out of 304 samples who had completed the questionnaire, 191 were women (62.8\%). The highest frequency in education belonged to the bachelor's degree which were 98 people (33.6\%) and the highest frequency was in the age group 29-40 years. which were 136 individuals (44.7\%) (Table 1).

Table 1: The demographics of participants

\begin{tabular}{|c|c|c|}
\hline \multicolumn{2}{|l|}{ Variable } & \multirow{2}{*}{$\begin{array}{l}\mathrm{N}(\%) \\
113(37.2 \%)\end{array}$} \\
\hline Gender & Male & \\
\hline & Female & $191(62.8 \%)$ \\
\hline & Missing & 0 \\
\hline \multirow[t]{5}{*}{ Age } & $18-28$ & $77(25.3 \%)$ \\
\hline & $29-40$ & $136(44.7 \%)$ \\
\hline & $41-59$ & $88(28.9 \%)$ \\
\hline & 60 & $2(0.7 \%)$ \\
\hline & Missing & $1(0.3 \%)$ \\
\hline \multirow[t]{10}{*}{ Job } & Student & $29(9.5 \%)$ \\
\hline & Housewife & $55(18.1 \%)$ \\
\hline & Teacher & $15(4.9 \%)$ \\
\hline & Employee & $59(19.4 \%)$ \\
\hline & Unemployed & $26(8.6 \%)$ \\
\hline & Private job & $34(11.2 \%)$ \\
\hline & Healthcare & $24(7.9 \%)$ \\
\hline & Retired & $34(11.2 \%)$ \\
\hline & Free & $27(8.9 \%)$ \\
\hline & Missing & $1(0.3 \%)$ \\
\hline \multirow[t]{7}{*}{ Education } & Less diploma & $18(5.9 \%)$ \\
\hline & Diploma & $62(20.4 \%)$ \\
\hline & Associate & $19(6.2 \%)$ \\
\hline & Bachelor & $102(33.6 \%)$ \\
\hline & Master & $76(25 \%)$ \\
\hline & Ph.D. & $26(8.6 \%)$ \\
\hline & Missing & $1(0.3 \%)$ \\
\hline & & Total su \\
\hline
\end{tabular}


In the fourth stage, the internal consistency of the entire questionnaire and its subscales was evaluated using Cronbach's alpha coefficient. The range of Cronbach's alpha varies between 0 and 1 , and 0.70 is usually considered as an acceptable criterion (42). The Cronbach's alpha of the entire questionnaire was a $=0.781$ which shows internal consistency between the questions.

KMO (Kaiser- Meyer Olkin) Test was employed to determine the sufficiency of the sample and Bartlett Test was utilized to review the significance of the research data correlation matrix. Barlett's and KMO were used to evaluate the quality of the factor analysis model. Bartlett's measure is a of the probability that the initial correlation matrix is an identity matrix and normally $<0.05$ and that $\mathrm{KMO}$ measures the degree of multicollinearity and should be greater than $0.50-0.60$. The $\mathrm{KMO}$ was 0.750 and the significance level of the Bartlett t's test of Sphericity was $\mathrm{P}<0.0001$ (Table 2 ).

Table 2: KMO and Bartlett's Test

\begin{tabular}{|c|c|c|}
\hline Kaiser-Meyer-Olkin Measure & of Sampling Adequacy. & 750 \\
\hline Bartlett's Test of Sphericity & Approx. Chi-Square & $1.101 \mathrm{E} 3$ \\
\hline & $\mathrm{df}$ & 190 \\
\hline Sig. & .000 & \\
\hline
\end{tabular}

Results of the EFA showed that 5 factors had eigenvalue more than one. The minimum accepted factor load in this study was 0.3. Therefore, 3 items were removed in this stage due to factor loads less than 0.3. The results of exploratory analysis showed that the highest percentage of total variance $(65.50 \%)$ is explained by the first 5 factors and the remaining total variance (34.50\%) is explained by the next 15 factors. In other words, factor analysis identified five factors with eigenvalue above one, which explained a total of $65.50 \%$ of the variance.

Then, in order to review the construct validity, structural equation modeling of first-order and second-order CFA was employed. The result of the first-order factor analysis test (Exploratory factor analysis) of the 22item risk perception questionnaire in 5 subscales of cognitive, emotional, political, social and cultural factors was a factor load in the range of 0.34 to 0.72 , which confirms the validity of all the constructs. At this stage, 2 items (questions 5 and 20) were deleted because they were less than 0.3 (Table 3).

Table 3: The result of the exploratory factor analysis of the 22-item the general perception of COVID-19 risk questionnaire 


\begin{tabular}{|c|c|c|c|}
\hline Row & Items & $\begin{array}{l}\text { Factor } \\
\text { loadings }\end{array}$ & Subscales \\
\hline 1 & $\begin{array}{l}\text { It is absolutely necessary to take measures to prevent Covid-19 } \\
\text { disease. }\end{array}$ & 0.58 & \multirow{4}{*}{$\begin{array}{r}\text { Cognitive } \\
\text { Factors }\end{array}$} \\
\hline 2 & $\begin{array}{l}\text { By following the health recommendations (such as: wearing a } \\
\text { mask and maintaining a physical distance) you can prevent } \\
\text { covid-19 disease. }\end{array}$ & 0.69 & \\
\hline 3 & Scientifically, it is quite possible to prevent Covid-19 disease. & 0.72 & \\
\hline 4 & $\begin{array}{l}\text { My knowledge of how Covid-19 disease is transmitted can lead } \\
\text { to preventive measures. }\end{array}$ & 0.61 & \\
\hline 6 & $\begin{array}{l}\text { Authority warnings are commensurate with the magnitude of } \\
\text { the risk of Covid-19 disease. }\end{array}$ & 0.47 & \multirow[t]{3}{*}{$\begin{array}{l}\text { Political } \\
\text { Factors }\end{array}$} \\
\hline 8 & $\begin{array}{l}\text { The performance of the officials is accompanied by hope and } \\
\text { encouragement to the people in the fight against Covid-19 } \\
\text { disease. }\end{array}$ & 0.68 & \\
\hline 9 & Executives make every effort to control Covid-19 disease. & 0.57 & \\
\hline 10 & $\begin{array}{l}\text { Carrying out preventive measures against covid-19 is } \\
\text { completely in accordance with religious recommendations. }\end{array}$ & 0.55 & \multirow{4}{*}{$\begin{array}{l}\text { Cultural } \\
\text { Factors }\end{array}$} \\
\hline 12 & $\begin{array}{l}\text { Clergy and cultural officials agree with scientists on the risk of } \\
\text { covid-19. }\end{array}$ & 0.65 & \\
\hline 14 & We Iranians believe we can defeat Covid- 19. & 0.34 & \\
\hline 15 & Iranian culture is action based on reason. & 0.47 & \\
\hline 13 & If we want, we can prevent Covid-19 disease. & 0.41 & \multirow{4}{*}{$\begin{array}{l}\text { Social } \\
\text { Factors }\end{array}$} \\
\hline 16 & It is the social duty of all of us to help control Covid-19 disease. & 0.35 & \\
\hline 18 & $\begin{array}{l}\text { It is necessary to inform the measures to prevent Covid-19 } \\
\text { disease in cyberspace. }\end{array}$ & 0.59 & \\
\hline 19 & $\begin{array}{l}\text { I participate in public cyberspace scans to prevent Covid-19 } \\
\text { disease. }\end{array}$ & 0.56 & \\
\hline 7 & Healthcare managers and staff exaggerate the risk of covid-19. & 0.65 & \multirow{5}{*}{$\begin{array}{l}\text { Emotional } \\
\text { Factors }\end{array}$} \\
\hline 11 & $\begin{array}{l}\text { Without doing anything, only relying on God can prevent covid- } \\
19 \text { disease. }\end{array}$ & 0.54 & \\
\hline 17 & $\begin{array}{l}\text { It is not my job to control Covid-19 disease; It is the duty of } \\
\text { others (scientists, officials, etc.). }\end{array}$ & 0.41 & \\
\hline 21 & $\begin{array}{l}\text { I feel that the risk of Covid-19 disease is not as high as they } \\
\text { say. }\end{array}$ & 0.55 & \\
\hline 22 & I am strong, Covid-19 disease can not hurt me. & 0.40 & \\
\hline \multicolumn{3}{|c|}{$\begin{array}{l}\text { + } 0.3 \text { Acceptable significance level } \\
\text { significance level }\end{array}$} & strong \\
\hline
\end{tabular}


Second-order factor analysis test was used to achieve a more accurate factor structure. Root mean residual (RMR, RMS or SRMS), goodness of fit (GFI), and adjusted goodness of fit index (AGFI), comparative fit index (CFI) and the second root mean square error of approximation (RMSEA) are among the most important and most used model fitness indices (23). The results of the measured indices of the constructs and their acceptable values are shown in Table 4. COVID-19 risk perception model was drawn based on the 20-item questionnaire and indices of the entire questionnaire were estimated. (Figure 2)

Table 4: Measured indices of the components of the general perception of COVID-19 risk questionnaire

\begin{tabular}{|l|l|l|l|l|l|l|}
\hline \multirow{2}{*}{ Index } & & CFI & AGFI & RMSEA & TLI & IFI \\
\cline { 2 - 7 } Component & $<3$ & $>0.9$ & $>0.9$ & $>0.08$ & $>0.9$ & $>0.9$ \\
\hline Cognitive Factors & 0.571 & 1.000 & 0.991 & 0.000 & 1.000 & 1.000 \\
\hline Emotional Factors & 0.717 & 1.000 & 0.986 & 0.000 & 1.000 & 1.000 \\
\hline Political Factors & 0.970 & 1.000 & 0.997 & 0.000 & 1.020 & 1.010 \\
\hline Social Factors & 0.970 & 1.000 & 0.998 & 0.000 & 1.040 & 1.000 \\
\hline Cultural Factors & 2.779 & 0.987 & 0.955 & 0.070 & 0.976 & 0.912 \\
\hline
\end{tabular}

\section{Discussion}

The present study was conducted to develop and determine the psychometric features of the COVID-19 public risk perception using confirmatory factor analysis with the maximum likelihood (ML) method or maximum probability in Iran. Two of the most important features of each instrument are its validity and reliability. The research results showed that the GPCOVID-19R questionnaire has the necessary validity and reliability. Technical studies of risk perception deepen the scientific perception and find the factors affecting an individual's risk perception $(11,43)$. Risk perception is conceptualized as a base for social resilience and with an innovate approach, it can lead to improved risk management plans through public cooperation(44). Because COVID-19 pandemic is a new phenomenon, there have not yet been many comprehensive studies regarding the public risk perception. A search through risk perception instruments of other natural disasters showed that in most cases, researcher-made questionnaires were used and there is no standard questionnaire.

In a systematic review study, it was determined that $90 \%$ of the studies regarding the infectious diseases risk perception of passengers are KAP studies and the survey questionnaire has been designed based on their knowledge, attitude, and performance(45). Effective Communication in Outbreak Management for Europe (ECOM) writes that each standard questionnaire regarding measurement of risk perception of 
infectious diseases should include the following features: Introduction, knowledge information about the disease context, serious understanding of the disease, anxiety and sensitivity to the disease, and information requirements(46). All of these have been considered in the present questionnaire.

This questionnaire was designed according to the scientific standard criteria based on 4 stages of Schneider. In the first stage, the operational definition of Covid-19 risk perception was obtained qualitatively from 10 experts. In the second stage, the items of the questionnaire of general risk perception of Covid-19 disease (136 items) were prepared. In the third stage of the research, the results of the study of face validity (qualitative and quantitative) and content with the help of a panel of experts and a survey led to 26 items. The remaining 26 questions received an acceptable score (0.5-1) in terms of the three indicators of relevance, simplicity and clarity. In the fourth stage, after performing and calculating Cronbach's alpha coefficient and evaluating the validity of the structure, the number of items reached 20.

In this study and in addition to qualitative content review, CVR and CVI were calculated to examine the content validity of the questionnaire, which led to elimination or merging of some items. The construct validity of the GPCOVID-19R questionnaire were reviewed by exploratory and confirmatory factor analysis on the remaining 26 items. Results of KMO measurement and Bartlett's test confirmed the factor analysis model and indicated its appropriateness. Results of special value show the existence of 5 questionnaire factors. The cut-off point of 3.0 was considered as the minimum required factor load for each item to stay in the questionnaire. Then, based on which item having the highest load factor on each of the five factors, it was considered as the item related to that factor.

In this research, the Cronbach's alpha coefficient of the designed questionnaire shows internal consistency between the items of the questionnaire, which confirms the reliability of GPCOVID-19R questionnaire.

The 20-item questionnaire of COVID-19 risk perception measurement, which has been made reliable and valid in this study, include 5 subscales: cognitive (4 items), emotional ( 5 items), cultural (4 items), and political (3 items) factors. These constructs are factors affecting the public risk perception of COVID-19.

Results of other studies indicate the effect of culture, knowledge and awareness, being responsible, and trust in officials on risk perception $(16,47-50)$. In an exclusive study by the same authors with the title of "Investigating the factors affecting Iranians' risk perception of COVID-19, some factors were identified and included in this study (49).

One of the strengths of this questionnaire is its easy application. It can be completed by health service providers in different mixed areas such as different groups of society, hospital, healthcare centers, students and healthcare workers in almost 10 minutes. Face and content validity confirmed the clarity of the statements.

The scoring method is based on 5-choice Likert scale for 15 questions from (disagree $=1$ ) to (agree $=5$ ), but it is reversed for Questions 6, 10, 19, 20, i.e. from (disagree $=5)$ to (agree $=1$ ). 
In order to score, the total score is calculated by summing the answers to each item. This scale has a score range of 20 to 100. A higher score indicates higher COVID-19 risk perception. Score interpretation is such that a score of 20 to 39 indicates poor risk perception, a score between 40 to 59 means moderate, 60 to 79 is good and 80 to 100 indicates excellent or desirable risk perception.

\section{Abbreviations \\ Declarations}

- Ethics approval and consent to participate: This study was confirmed by the ethics committee of Sabzevar University of Medical Sciences under number IR.MEDSAB.REC.1399.075. All methods were carried out in accordance with relevant guidelines and regulations.

- Consent to participate: Informed consent was obtained from all individual participants included in the study.

- Consent to publish: Not applicable

- Availability of data and materials: The datasets used and/or analyzed during the current study are available from the corresponding author on reasonable request.

- Competing interests: The authors declare that they have no competing interests

- Funding: Nil

- Authors' Contributions: ES has been involved in designing the work, interpreting the results, and was a major contributor in writing the manuscript. FG has been involved in designing the work, interpreting the results, and was a major contributor in writing the manuscript. All authors read and approved the final manuscript.

-Acknowledgements: The authors sincerely thank all the professors who were present at the panel of experts and the participants in this project.

\section{Abbreviations}

CFA:

Confirmatory factor analysis

CFI:

Comparative fit index

CVI: 
Content validity index

\section{CVR:}

Content validity ratio

\section{GPCOVID-19R:}

General perception of covid-19 risk

\section{EFA:}

Exploratory factor analysis

GFI:

Goodness of fit index

NFI:

Normed fit index

NNFI:

Non-normed fit index

\section{RMSEA:}

Root mean square error of approximation;

\section{SRMR:}

Standardized root mean square residual

\section{Declarations}

Ethics approval and consent to participate: This study was confirmed by the ethics committee of Sabzevar University of Medical Sciences under number IR.MEDSAB.REC.1399.075. All methods were carried out in accordance with relevant guidelines and regulations.

Consent to participate: Informed consent was obtained from all individual participants included in the study.

Consent to publish: Not applicable

Availability of data and materials: The datasets used and/or analyzed during the current study are available from the corresponding author on reasonable request. 
Competing interests: The authors declare that they have no competing interests

\section{Funding: Nil}

Authors' Contributions: ES has been involved in designing the work, interpreting the results, and was a major contributor in writing the manuscript. FG has been involved in designing the work, interpreting the results, and was a major contributor in writing the manuscript. All authors read and approved the final manuscript.

Acknowledgements: The authors sincerely thank all the professors who were present at the panel of experts and the participants in this project.

\section{References}

1. Sohrabi C, Alsafi Z, O'Neill N, Khan M, Kerwan A, Al-Jabir A, et al. World Health Organization declares Global Emergency: A review of the 2019 Novel Coronavirus (COVID-19). International Journal of Surgery. 2020.

2. https://www.who.int/publications/m/item/weekly-epidemiological-update--22-december-2020 [Internet]. 2020.

3. Smith R. Responding to global infectious disease outbreaks: lessons from SARS on the role of risk perception, communication and management. Social science \& medicine. 2006;63(12):3113-23.

4. Hellewell J, Abbott S, Gimma A, Bosse NI, Jarvis Cl, Russell TW, et al. Feasibility of controlling COVID19 outbreaks by isolation of cases and contacts. The Lancet Global Health. 2020;8(4):488-96.

5. Vartti A-M, Oenema A, Schreck M, Uutela A, Zwart Od, Brug J, et al. SARS knowledge, perceptions, and behaviors: a comparison between Finns and the Dutch during the SARS Outbreak in 2003. International journal of behavioral medicine. 2009;16(1):41-8.

6. Yeung N, Lau J, Choi K, Griffiths S. Population responses during the pandemic phase of the influenza A (H1N1) pdm09 Epidemic, Hong Kong, China. Emerging infectious diseases. 2017;23(5):813-5.

7. Aakko E. Risk communication, risk perception, and public health. Wisconsin Medical Journal. 2004;103(1):25-8.

8. Brug J, Aro AR, Richardus JH. Risk perceptions and behaviour: towards pandemic control of emerging infectious diseases. Springer; 2009.

9. Jones E, Faas A, Murphy A, Tobin G, Whiteford L, McCarty C. Cross-cultural and site-based influences on demographic, well-being, and social network predictors of risk perception in hazard and disaster settings in Ecuador and Mexico. Human nature. 2013;24(1):5-32.

10. Zakerimoghadam M, Sanaie N, Ebadi A, Shali M. Concept analysis of heart disease risk perception from health professionals perspective: Hybrid model. Iranian Journal of Cardiovascular Nursing. 2017;6(3):68-79.

11. Bourque LB, Regan R, Kelley MM, Wood MM, Kano M, Mileti DS. An examination of the effect of perceived risk on preparedness behavior. Environment and behavior. 2013;45(5):615-49. 
12. Siegrist M, Cvetkovich G. Perception of hazards: The role of social trust and knowledge. Risk analysis. 2000;20(5):713-20.

13. Dake K. Myths of nature: Culture and the social construction of risk. Journal of Social issues. 1992;48(4):21-37.

14. Elchardus M, Groof SD, Smits W. Rational Fear or Represented Malaise: A Crucial Test of Two Paradigms Explaining Fear of Crime. Sociological Perspectives. 2008;51(3).

15. Dryhurst S, Schneider CR, Kerr J, Freeman AL, Recchia G, Van Der Bles AM, et al. Risk perceptions of COVID-19 around the world. Journal of Risk Research. 2020:1-13.

16. Jones EC, Faas AJ, Murphy AD, Tobin GA, Whiteford LM, McCarty C. Cross-cultural and site-based influences on demographic, well-being, and social network predictors of risk perception in hazard and disaster settings in Ecuador and Mexico. Human nature. 2013;24(1):5-32.

17. Oltedal S, Moen B-E, Klempe H, Rundmo T. Explaining risk perception: An evaluation of cultural theory. Rotunde. 2004;85:1-33.

18. Renn O, Rohrmann B. Cross-Cultural Risk Perception: Springer; 2000.

19. Benthin A, Slovic P, Severson H. A psychometric study of adolescent risk perception. Journal of adolescence. 1993;16(2):153-68.

20. Douglas M, Wildavsky A. How can we know the risks we face? Why risk selection is a social process 1. Risk analysis. 1982;2(2):49-58.

21. Rippl S. Cultural theory and risk perception: a proposal for a better measurement. Journal of risk research. 2002;5(2):147-65.

22. Polit D, Beck C. Nursing research: Principles and methods: Lippincott Williams \& Wilkins; 2004.

23. Bandari R H-KM, Miremadi M, Mohebbi L, Montazeri A. The Iranian version of geriatric anxiety inventory (GAI-P): a validation study. Health and Quality of Life Outcomes. 2019;17(1):118.

24. Munro BH. Statistical methods for health care research: lippincott williams \& wilkins; 2005.

25. Renn O. Risk perception and communication: lessons for the food and food packaging industry. Food additives and contaminants. 2005;22(10):1061-71.

26. Bird DK. The use of questionnaires for acquiring information on public perception of natural hazards and risk mitigation-a review of current knowledge and practice. Natural Hazards and Earth System Sciences. 2009;9(4):1307.

27. Bird D, Dominey-Howes D. Testing the use of a 'questionnaire survey instrument'to investigate public perceptions of tsunami hazard and risk in Sydney, Australia. Natural Hazards. 2008;45(1):99-122.

28. Samadipour E SH, Ravaghi M. Disater risk perception: designing a model for Iran.. In: sciences IUom, editor. Tehran, Iran: Iran University 2019.

29. Samadipour E, Ghardashi F. Factors Influencing Iranians' Risk Perception of Covid-19. Journal of Military Medicine. 2020;22(2):122-9.

30. LoBiondo-Wood G HJ. Nursing Research: Methods and Critical Appraisal for Evidence-Based Practice, 8e (Nursing Research: Methods, Critical Appraisal \& Utilization). 8th Edition ed. St.Louis: Mosby. 2013. 
31. LoBiondo-Wood G, Haber J, Berry C, Yost J. Study guide for nursing research-e-book: methods and critical appraisal for evidence-based practice: Elsevier Health Sciences; 2013.

32. Graneheim UH, Lundman B. Qualitative content analysis in nursing research: concepts, procedures and measures to achieve trustworthiness. Nurse education today. 2004;24(2):105-12.

33. Lawshe CH. A quantitative approach to content validity 1. Personnel psychology. 1975;28(4):563-75.

34. Polit DF, Beck CT, Owen SV. Is the CVI an acceptable indicator of content validity? Appraisal and recommendations. Research in nursing \& health. 2007;30(4):459-67.

35. Polit DF, Yang FM. Measurement and the measurement of change: Wolters Kluwer Philadelphia, PA; 2016.

36. Ayre C, Scally A. Critical Values for Lawshe's Content Validity Ratio: Revisiting the Original Methods of Calculation. Measurement and Evaluation in Counseling and Development. 2014;47(1):79-86.

37. Ebadi A, Zarshenas L, Rakhshan M, Zareiyan A, Sharifnia S, Mojahedi M. Principles of scale development in health science. Tehran: jamee negar. 2017.

38. Brinkman W-P. Design of a questionnaire instrument. Handbook of mobile technology research methods. 2009:31-57.

39. Burns N GS. The practice of nursing research conduct, critique and utilization. St. te, editor: Louis: Saunders; 2005.

40. Ayre C, Scally AJ. Critical values for Lawshe's content validity ratio: revisiting the original methods of calculation. Measurement and Evaluation in Counseling and Development. 2014;47(1):79-86.

41. BHh M. Statistical methods for health care researc: lippincott williams \& wilkins 2005.

42. Al-Osail AM, Al-Sheikh MH, Al-Osail EM, Al-Ghamdi MA, Al-Hawas AM, Al-Bahussain AS, et al. Is Cronbach's alpha sufficient for assessing the reliability of the OSCE for an internal medicine course? BMC research notes. 2015;8(1):582.

43. Shreve C, Fordham M, Anson S, Watson H, Hagen K, Wadhwa K, et al. Report on risk perception and preparedness. TACTIC project, North Umbria University. 2014.

44. Arab MA. Creating an Organizational Safety Culture: A Strategy to Increase Employee Risk Understanding. 8th Specialized Congress of Standards for Medical Equipment and Materials in the Field of Infection Control and Sterilization; Tehran: civilica; 2019.

45. Sridhar S, Régner I, Brouqui P, Gautret P. Methodologies for measuring travelers' risk perception of infectious diseases: A systematic review. Travel Medicine and Infectious. 2016;14(4):360-72.

46. Helene Voeten GR-R. Standard questionnaire on risk perception of an infectious disease outbreak. 7, editor. Netherlands: Municipal Public Health Service Rotterdam-Rijnmond (GGD); 2015.

47. Xie XL, Lo AY, Zheng Y, Pan J, Luo J. Generic security concern influencing individual response to natural hazards: evidence from Shanghai, $C$ hina. Area. 2014;46(2):194-202.

48. Damm A, Eberhard K, Sendzimir J, Patt A. Perception of landslides risk and responsibility: a case study in eastern Styria, Austria. Natural hazards. 2013;69(1):165-83. 
49. Terpstra T. Emotions, trust, and perceived risk: Affective and cognitive routes to flood preparedness behavior. Risk Analysis: An International Journal. 2011;31(10):1658-75.

50. Samadipour E, Ghardashi F, Aghaei N. Evaluation of Risk Perception of Covid-19 Disease: A Community-based Participatory Study. Disaster Medicine and Public Health Preparedness. 2020:1-20.

\section{Figures}

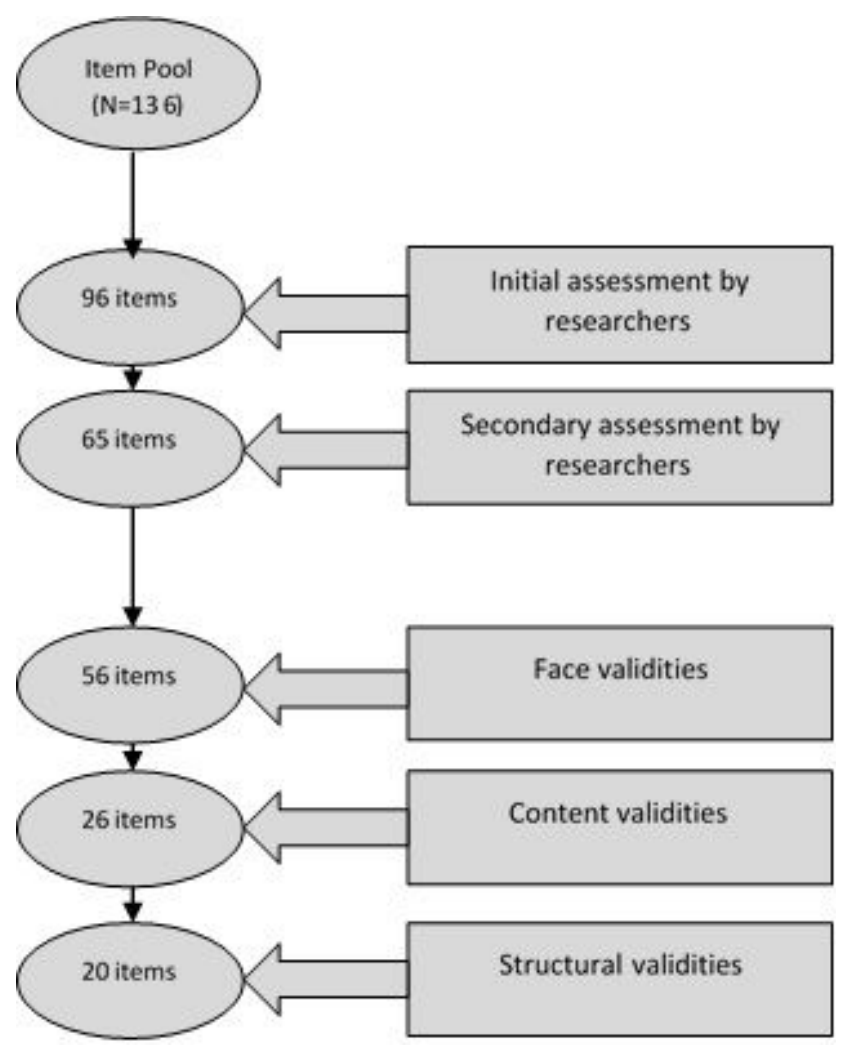

\section{Figure 1}

The flowchart summarizing the psychometric stages of "general perception of COVID-19 risk" questionnaire 


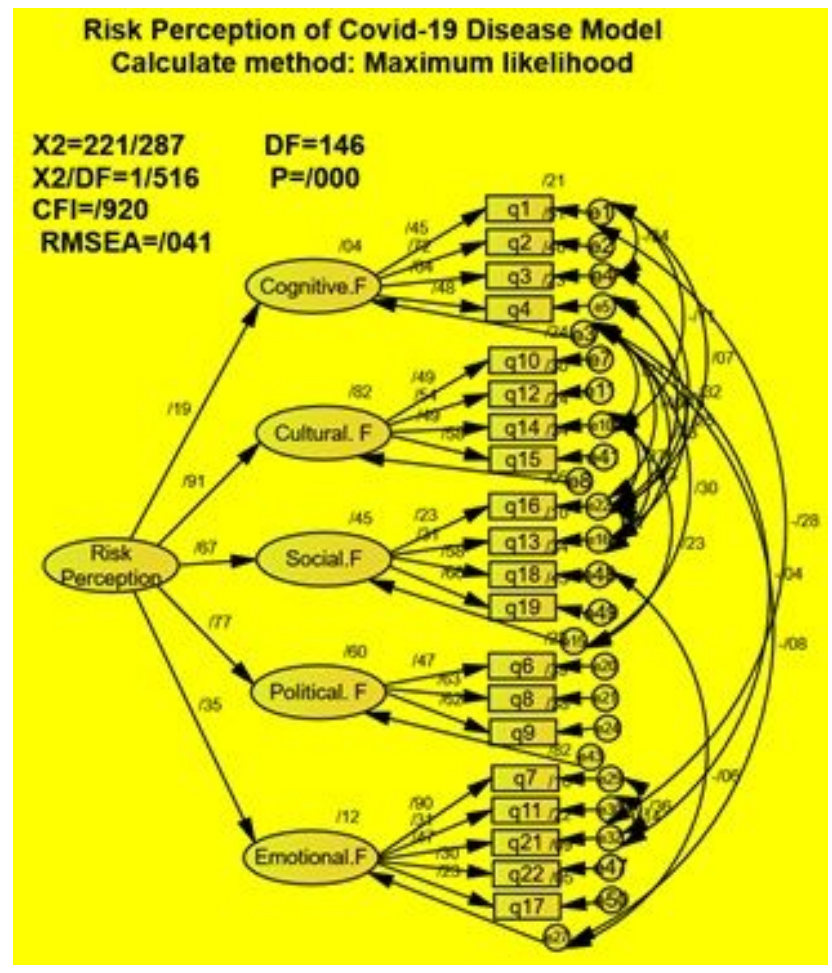

Figure 2

Structural model of the general perception of COVID-19 risk questionnaire 